\title{
The Effect of Tai Chi Service Program Applied to the Elderly by Nursing Students
}

\author{
Young-Ju Jee1)
}

\begin{abstract}
This study intended to provide desirable health information to elderly enrolled in elderly community universities through Tai Chi program implemented by nursing students as a voluntary service-related with their major. The data were collected from Sep. 1, 2016 to May 1, 2017, and 50 subjects were selected for experimental and control group, respectively, though data of 47 subjects (experimental group $n=23$, control group $\mathrm{n}=24$ ) were used in the analysis due to withdrawal within study period. The general characteristics, physical and psychological health status, and osteoarthritis index were expressed as real numbers and percentages. The hypotheses were tested using ANOVA and ANCOVA. Two groups were treated as homogenous one based on the result of homogeneity test. The statistically significant differences between experimental and control groups were observed in left anterior femoral muscle $(t=2.48, p=.018)$, left posterior femoral muscle $(\mathrm{F}=5.01, \mathrm{p}=.013)$, balance $(\mathrm{t}=2.09, \mathrm{p}=.001)$, osteoarthritis index $(\mathrm{t}=2.12$, $\mathrm{p}=0.012)$, fall efficacy $(\mathrm{t}=1.32, \mathrm{p}=.012)$, and fear of falling $(\mathrm{t}=-3.52, \mathrm{p}<.001)$ but not in right anterior femoral muscle ( $\mathrm{t}=1.61, \mathrm{p}=0.116)$ and right posterior femoral muscle $(\mathrm{F}=1.29, \mathrm{p}=0.289)$.
\end{abstract}

Keywords: Nursing Students, Elderly, Tai Chi, Service, Osteoarthritis

\section{Introduction}

The universities, in recent, have been emphasizing social service function as one of the strategies for their competition in university education. This trend is also confirmed by the fact that the number of universities offering social service courses for the practice of educational ideology is increasing[1]. In addition to the increasing need for professional volunteer activities of university students, quantitative expansion by the spread of learning through service is another characteristic[2]. The major-related service activity has significant meaning in that these activities, through pre-experience of future occupation, strengthen the attitude of awareness of students and is helpful in their selection and decision on the future occupation[3][4].

The major-related service activity, given these aspects, is considered to have vast usefulness in nursing education.

Received(October 21, 2019), Review Result(1st: November 13, 2019, 2nd: December 13, 2019), Accepted(February 20, 2020)

1) (Professor) 51767 Department of Nursing, Kyungnam University, Woryeongbuk 16-gil Masanhappo-gu, Changwon-si, Gyeongsangnam-do, Korea

email: jeeyoungju@kyungnam.ac.kr 
For the development of specialized voluntary activities by university students where the community and university, in cooperation with each other, solve community problems, universities need to play leading role in establishing a coordinative system with local voluntary group[5]. The participation of nursing students in voluntary service programs for the health of seniors in community senior college is expected to have desirable consequence because the students participate in volunteer activities in their areas of interest, resulting in a stronger motivation for participation and a commitment to action[4].

Osteoarthritis is one of the most common chronic degenerative disease associated with aging evidenced by the $42.3 \%$ of prevalence in the elderly over 70 years old[6]. The progression of degenerative changes in the periarticular tissue and subchondral bone causes pain[7], therefore, patients with this disease should learn self-management skills that enable them, for the rest of life, to maintain their daily lives while controlling disease state[8]. Nevertheless, most patients with osteoarthritis often stop exercising within a year[9].

This means that, in the management of elderly patients with osteoarthritis, the establishment of self-help management team and selection of leader among team members to maximize the long-term sustained exercise effect and minimize the reasons for stopping the exercise. The Tai Chi exercise, a traditional Chinese martial art with elegant and slow action, is a low-intensity mind and body exercise focusing on health promotion. This exercise has advantages of easy accessibility (Lam, 2000), because it does not require any special facility or equipment in performing various motions with flexed knee postures[10].

This exercise is, therefore, suitable for being introduced to elderly people in the community where there may be a gap in environments. The changes in physical health status through the Tai Chi exercise include improvement in flexibility and balance[11-13], and desirable change in helpful in carrying out daily activities, and improving physical and mental health status through Tai Chi exercises[14].

As for the perceived changes in health status, Park[15] reported that patients with osteoarthritis undergoing the Tai Chi exercise experienced decreased pain at eight weeks and 12 weeks and in Lee's[16] study decrease in joint pain and stiffness were observed. In addition, Tai Chi exercise experienced changes in psychological health status include reducing the fear of falling[17][18] and decrease in the number of falling due to confidence improvement[18].

The purpose of this study was to investigate the effects of Tai Chi exercise service by nursing students on the maintenance and improvement of physical health status, osteoarthritis index, and psychological health status of the elderly in the community. Furthermore, the result of this study is expected to contribute to the development of an effective model of self-help 
exercise program for patients with osteoarthritis.

\section{Method}

\subsection{Purpose}

The purpose of this study was to investigate the effects of Tai Chi exercise service by nursing students for the patients with osteoarthritis and the specific purposes are as follows:

1) To investigate the general characteristics of community elderly patients over 65 years old with osteoarthritis enrolled in elderly university.

2) To determine the changes in physical and psychological health status and osteoarthritis index after applying six-weeks program of Tai Chi exercise (two sessions per a week) in community elderly patients over 65 years old with osteoarthritis enrolled in elderly university

\subsection{Design}

This study is an equivalent quasi-experimental one.

\subsection{Subjects and Data Collection}

The subjects were elderly patients over 65 years old with osteoarthritis enrolled in two elderly universities with similar demographic distribution and economic condition located in C city. These two universities were assigned to the experimental and the control site, respectively, by using drawing coin throwing and, considering withdrawal rate, fifty subjects were recruited for each group. Of the participants, 53 were eliminated due to directors and absences, and 47 data were used for analysis.

\subsection{Data Analysis}

The collected data was analyzed by following statistics using SPSS Win 21.0 program

1) The real number and percentage were used in expressing demographic characteristics, physical and psychological health status and osteoarthritis index.

2) The ANCOVA was used in testing hypothesis. 


\section{Results}

\subsection{Homogeneity Test}

The results of homogeneity test showed that the proportions of male, age, marriage, single family were higher in control group than those in experimental one while the BMI and proportions and families of two or over members were higher in experimental group compared to experimental one. The differences, however, did not reach .05 or over of $p$ value, indicating that two groups have statistically heterogenous characteristics.

[Table 1] Homogeneity Test for Demographic Characteristics

$(\mathrm{N}=47)$

\begin{tabular}{|c|c|c|c|c|c|}
\hline \multicolumn{2}{|c|}{ Characteristics } & Experimental $(\mathrm{n}=23)$ & $\underline{\text { Control }(n=24)}$ & X2ort & $\mathrm{P}$ \\
\hline \multirow{2}{*}{ Gender } & Male & $7(30.0)$ & $9(36.0)$ & \multirow{2}{*}{0.22} & \multirow{2}{*}{.601} \\
\hline & Female & $16(70.0)$ & $15(64.0)$ & & \\
\hline \multicolumn{2}{|c|}{ Age } & 74.18(6.99) & $75.20(6.22)$ & -0.87 & .481 \\
\hline \multicolumn{2}{|c|}{ BMI } & $26.01(4.17)$ & $25.55(3.14)$ & 1.01 & .250 \\
\hline & Marriage & $11(48.0)$ & 13(54.17) & \multirow[b]{2}{*}{0.09} & \multirow[b]{2}{*}{.666} \\
\hline $\begin{array}{l}\text { Marital } \\
\text { status }\end{array}$ & $\begin{array}{l}\text { Single (divorced, } \\
\text { widowed, } \\
\text { separated) }\end{array}$ & $12(52.0)$ & $11(45.83)$ & & \\
\hline \multirow{3}{*}{ Family number } & 1 & $5(21.7)$ & $6(25.0)$ & \multirow{3}{*}{0.88} & \multirow{3}{*}{.151} \\
\hline & 2 & $12(52.2)$ & $11(45.8)$ & & \\
\hline & More than 3 & $6(26.1)$ & $7(29.2)$ & & \\
\hline \multirow[b]{2}{*}{ Falls experience } & Yes & $8(34.8)$ & $8(33.3)$ & \multirow{2}{*}{0.01} & \multirow{2}{*}{.832} \\
\hline & No & $15(65.2)$ & $16(66.7)$ & & \\
\hline \multirow{4}{*}{$\begin{array}{l}\text { Chronic disease } \\
\text { (Multiple } \\
\text { responses } \\
\text { possible) }\end{array}$} & Osteoarthritis & 13 & 15 & & \\
\hline & $\begin{array}{l}\text { Rheumatoid } \\
\text { osteoarthritis }\end{array}$ & 2 & 4 & & \\
\hline & Diabetes & 4 & 7 & & \\
\hline & Hypertension & 16 & 18 & & \\
\hline
\end{tabular}




\subsection{Comparison of Physical and Psychological Health Status and Osteoarthritis Index}

The results of the pre-measurement using femoral muscle strength showed difference between left $(p=.005)$ and right $(p=0.045)$ side of posterior femoral muscle, thus these were used as covariate, and post-measurement values were dependent variables in ANCOVA. There was statistically significant difference between two groups in left anterior femoral muscle $(t=2.48$, $\mathrm{p}=0.018)$ but not in right one $(t=1.61, p=0.116)$.

This pattern was same for the posterior femoral muscle (right one, $F=1.29, \mathrm{p}=0.289$; left one, $\mathrm{F}=5.01, \mathrm{p}=0.013$ ). There was significant difference between two groups in balance in one-leg standing $(\mathrm{t}=2.09, \mathrm{p}=0.001)$ but not in waist flexibility $(\mathrm{t}=1.63, \mathrm{p}=0.112)$

There were also a statistically significant difference between two groups in osteoarthritis index $(t=2.12, p=0.012)$, and for the psychological health status, fall efficacy $(t=1.32, p=0.012)$, and fear of falling $(t=-3.52, \mathrm{p}<.001)$ in psychological health status.

[Table 2] Comparison of Physical Health Status, Osteoarthritis Index, and Psychological Health Status of Groups

$(\mathrm{N}=47)$

\begin{tabular}{|c|c|c|c|c|c|c|c|}
\hline \multirow{2}{*}{\multicolumn{4}{|c|}{ Variable }} & Experimental $(\mathrm{n}=23)$ & Control $(n=24)$ & \multirow{3}{*}{$\begin{array}{l}t \text { or } \\
F \\
1.65\end{array}$} & \multirow{3}{*}{$\begin{array}{c}\mathrm{P} \\
0.108\end{array}$} \\
\hline & & & & $\mathrm{M}(\mathrm{SD})$ & $\mathrm{M}(\mathrm{SD})$ & & \\
\hline \multirow{8}{*}{$\begin{array}{l}\text { Muscle } \\
\text { Strength }\end{array}$} & \multirow{4}{*}{ Anterior } & \multirow{2}{*}{ Rt. } & Pre. & $2.24(0.31)$ & $2.03(0.42)$ & & \\
\hline & & & Pos. & $2.71(0.55)$ & $2.40(0.59)$ & 1.61 & 0.116 \\
\hline & & \multirow{2}{*}{ Lt. } & Pre. & $2.14(0.33)$ & $1.090(0.56)$ & 1.57 & 0.125 \\
\hline & & & Pos. & $2.73(0.07)$ & $2.24(0.58)$ & 2.48 & 0.018 \\
\hline & \multirow{4}{*}{ Posterior } & \multirow{2}{*}{ Rt. } & Pre. & $2.43(0.39)$ & $2.15(0.41)$ & 2.08 & 0.045 \\
\hline & & & Pos. & $2.61(0.49)$ & $2.24(0.39)$ & 1.29 & 0.289 \\
\hline & & \multirow{2}{*}{ Lt. } & Pre. & $2.18(0.36)$ & $1.62(0.72)$ & 2.98 & 0.005 \\
\hline & & & Pos. & $2.43(0.57)$ & $2.06(0.57)$ & 5.01 & 0.013 \\
\hline \multirow{2}{*}{ Flexibility } & \multirow{2}{*}{ Back } & \multicolumn{2}{|c|}{ Pre. } & $16.00(6.81)$ & $12.89(4.58)$ & 1.61 & 0.117 \\
\hline & & \multicolumn{2}{|c|}{ Pos. } & $16.33(6.75)$ & $13.50(2.96)$ & 1.63 & 0.112 \\
\hline \multirow{2}{*}{ Balance } & \multirow{2}{*}{$\begin{array}{l}\text { One leg } \\
\text { stand }\end{array}$} & \multicolumn{2}{|c|}{ Pre. } & $1.37(0.98)$ & $2.50(0.23)$ & 2.06 & 0.153 \\
\hline & & \multicolumn{2}{|c|}{ Pos. } & $3.02(2.47)$ & $2.25(2.82)$ & 2.09 & 0.001 \\
\hline
\end{tabular}


The Effect of Tai Chi Service Program Applied to the Elderly by Nursing Students

\begin{tabular}{|c|c|c|c|c|c|}
\hline \multirow{2}{*}{ Osteoarthritis Index } & Pre. & $106.86(11.25)$ & $110.0(10.43)$ & 2.62 & 0.772 \\
\cline { 2 - 6 } & Pos. & $92.43(10.21)$ & $112.4(15.25)$ & 2.12 & 0.012 \\
\hline \multirow{3}{*}{ Fall efficacy } & Pre. & $42.76(14.60)$ & $40.36(12.96)$ & 1.52 & 0.767 \\
\cline { 2 - 6 } & Pos. & $45.22(15.55)$ & $40.19(11.26)$ & 1.32 & 0.012 \\
\hline \multirow{2}{*}{ Fear of falling } & Pre. & $16.70(11.42)$ & $17.58(10.85)$ & 2.54 & 0.815 \\
\cline { 2 - 6 } & Pos. & $10.57(9.70)$ & $18.25(11.35)$ & -3.52 & $<.001$ \\
\hline
\end{tabular}

\section{Discussion}

This study intended to provide desirable health information to elderly enrolled in elderly community universities through Tai Chi program implemented by nursing students as a voluntary service-related with their major. The nursing students provided Tai Chi service program for elderly over 65 years old enrolled in elderly university and the effects of the program on their physical and psychological health status and osteoarthritis index. The statistically significant differences between experimental and control groups were observed in left anterior femoral muscle $(t=2.48, p=.018)$, left posterior femoral muscle $(F=5.01, p=.013)$, balance $(t=2.09, p=.001)$, osteoarthritis index $(t=2.12, p=0.012)$, fall efficacy $(t=1.32, p=.012)$, and fear of falling $(t=-3.52, p<.001)$ but not in right anterior femoral muscle $(t=1.61, p=0.116)$ and right posterior femoral muscle $(\mathrm{F}=1.29, \mathrm{p}=0.289)$.

These results show that the Tai Chi service program conducted by nursing students is an appropriate nursing intervention program that has positive effects on the physical and psychological health status and osteoarthritis index of the elderly. In addition, it was a meaningful activity for the university to satisfy its responsibilities of community service. Based on the results of this study, it is recommended for the departments of the university to set up a service plan for the community, which will provide students with indirect experience in their future activities linked to major and community around the university with benefit from cooperation. Given that the indirect benefit of improvement in intimacy between generations was observed in this study, future studies on improvement of intimacy of the generation through the elderly service program by college students is recommended.

\section{Acknowledgement}

This work was supported by Kyungnam University Foundation Grant, 2016 


\section{References}

[1] Survey Analysis of University's Participation in Community Service, Korean University Council for Social Service, (2010)

[2] Korean University Council for Social Service, Study on Satisfaction Level of Volunteer Learning Related to All Major study, Korean University Council for Social Service Research Report, (2008)

[3] Sun, Woo-Hyun, A Study device of university social service activation, Honam University, Kwangju, Unpublished Master Dissertation, (2000)

[4] Kim, Sung Yong, The Study for Special Welfare to Graduate Student's Break away Volunteer - Focusing on Myung-Ji University Social Wefare Postgraduate Student's Recognition, Myung-Ji University, Seoul, Unpublished Master Dissertation, (2006)

[5] Seo, Seong Min, Study on Voluntary Activities by University Students and on Activation Methods, Sogang University, Seoul, Unpublished Master Dissertation, (2007)

[6] The third Korea National Health Nutrition Examination Survey, (KNHANES III), Ministry of Health and Welfare, Korea Institute for Health and Social Affairs, (2005)

[7] Hurley, M. V., Mitchell, H. L., Walsh, N., In osteoarthritis, the psychosocial benefits of exercise are as improvement as physiological improvements, Exercise and Sports Sciences Reviews, (2003), Vol.31. No,3, pp.138-143.

[8] Lee, E. O., Suh, M. J., Kang, H. S., Lim, N. Y., Han, S. S., Song, K. Y., Eum, O. B., Lee, I. O., Kim, M. R., \& Choi, H. J., The Effect of Self-Help Program for Promotion of Health for Arthritis Patients at various Health Centers in Seoul, Journal of Muscle and Joint Health, (1998), Vol.5. No,2, pp.155-173.

[9] Sohng, K. Y., Evaluation of the self-help program and operational strategies, Journal of Muscle and Joint Health, (2000), Vol.7, No,2, pp.358-363.

[10] Lam, P., A handbook for Tai Chi for arthritis, Narwee: East Acton Publishing, (2000)

[11] Song, R., Lee, E., Bae, S., Lam, P., Effects of Tai Chi or Self-help Program on Balance, Flexibility, Oxygen Consumption, and Muscle Strength in Women with Osteoarthritis, Journal of Korean Academy of Fundamentals of Nursing, (2009), Vol.16, No.1, pp.30-38.

[12] Song, K. Y., Moon, J. S., A Survey on Activities and Fear of Falling in the Home-dwelling Elderly in Seoul and Gyonggi-do, Journal of Korean Academy of Community Health Nursing, (2003), Vol.14, No.4, pp.676-685.

[13] Li, Y., Devault, C. N., Van, O. S., Effects of extended Tai Chi intervention on balance and selected motor functions of the elderly, The American Journal of Chinese Medicine|, (2007), Vol.35, No.3, pp.383-391. DOI: $10.1142 / \mathrm{S} 0192415 \mathrm{X} 07004904$

[14] Fransen, M., Nairn, L., Winstanley, J., Lam, P., Edmonds, J., Physical activity for osteoarthritis management: a randomized controlled clinical trial evaluating hydrotherapy or Tai Chi classes, Arthritis Rheum, (2007), Vol.57, No.3, pp.407-414. DOI: 10.1002/art.22621 
[15] Park, Y. J., Effects of Tai Chi exercise program on self-efficacy, pain and physical function in patients with osteoarthritis, Chonnam National University, Kwang-Ju, Unpublished Doctoral Dissertation, (2004)

[16] Lee, H. Y., Comparison of effects among Tai-Chi exercise, aquatic exercise, and a self-help program for patients with knee osteoarthritis, Journal of Korean Academy of Nursing, (2006), Vol.36, No.3, pp.571-580. DOI: $10.4040 / \mathrm{jkan} .2006 .36 .3 .571$

[17] Song, R., Eom, A., Lee, E., Lam, P., Bae, S., Effects of Tai Chi combined with Self-help Program on Arthritic Symptoms and Fear of Falling in Women with Osteoarthritis, Journal of Muscle and Joint Health, (2009), Vol.16, No.1, pp.46-54.

[18] Sattin, R. W., Easley, K. A., Wolf, S. L., Chen, Y., Kutner, M. H., Reduction in fear of falling through intense tai chi exercise training in older, transitionally frail adults, Journal of the American Geriatrics Society, (2005), Vol.53, No.7, pp.1168-1178. DOI: 10.1111/j.1532-5415.2005.53375.x 